\title{
Deficiência, Reconhecimento e (In)Justiça: apontamentos sobre a situação de mulheres com deficiência encarceradas e encarceradas mães de pessoas com deficiência no Brasil
}

Disability, Recognition and (In)Justice: notes on the situation of incarcerated women and incarcerated women mothers of people with disabilities in Brazil

Discapacidad, Reconocimiento y (In)Justicia: notas sobre la situación de las mujeres con discapacidad encarceladas y de las encarceladas madres de personas con discapacidad en Brasil

Jacqueline de Souza Gomes

Professora pós-doutora da Universidade Federal Fluminense, Niterói, RJ, Brasil

E-mail: jsgomes@id.uff.br ORCID: https://orcid.org/0000-0002-8609-5893

Recebido em 12 de setembro de 2021

Aprovado em 22 de dezembro de 2021

Publicado em 27 de dezembro de 2021

\section{RESUMO}

Contradições e opressões invisibilizadas pulsam se atentamos à situação das mulheres, especialmente as com deficiência ou as mães de pessoas com deficiência, no sistema prisional brasileiro. $O$ contexto prisional reproduz uma sociedade sexista, patriarcal e conservadora, excluindo as especificidades que compõem o universo das mulheres, seja em relação à orientação sexual, raça, idade, deficiência, maternagem, nacionalidade, etc. À luz da justiça como reconhecimento, utilizando-nos da pesquisa documental e bibliográfica, refletimos sobre como o negligenciamento da diversidade de experiências de reconhecimento violam identidades e negam direitos básicos às mulheres com deficiência encarceradas bem como às encarceradas mães de pessoas com deficiência. Nosso objetivo foi investigar se há ausência de reconhecimento destas mulheres expressa pela precariedade de dados, estudos e indicadores, a ocultar, por consequência, violações no acesso à direitos básicos destas e de sua prole. A argumentação está estruturada em dois eixos, a saber: a) análise crítica sobre a invisibilidade dos estudos sobre mulheres com deficiência e encarceradas mães de pessoas com deficiência no Brasil à luz da justiça como reconhecimento; b) estudo de caso sobre direitos (e violações) das mães de pessoas com deficiência encarceradas a partir do Habeas Corpus Coletivo 165.704, que sinaliza a substituição da prisão cautelar por domiciliar de mães de menores de 12 anos e de pessoas com deficiência. Enquadrar a situação destas mulheres em termos de justiça como reconhecimento reverbera o caráter relacional da justiça e, a partir daí, reforça esta necessária discussão sobre a estruturação do nosso ethos social, que nos faz capacitistas e legitimadores/as de uma sociedade que pune pessoas pelo que são, não pelo que fazem. Palavras-chave: Deficiência; Encarceramento Feminino; Justiça como Reconhecimento. 
http://dx.doi.org/10.5902/1984686X67647

\section{ABSTRACT}

Invisible contradictions and oppressions rise if we pay attention to the situation of women, especially those with disabilities or mothers of people with disabilities, in the Brazilian prison system. Prison context reproduces a sexist, patriarchal and conservative society, excluding the specificities that compose the universe of women, whether in relation to sexual orientation, race, age, disability, motherhood, nationality, etc. In the light of justice as recognition and using documents and bibliographic research, this paper aims to reflect on how neglecting diversity of experiences of recognition violates identities and denies rights for imprisoned disabled women as well as imprisoned mothers of disabled people. Our goal was to investigate if there is a lack of recognition of these women expressed by the precariousness of data, studies, and indicators, which consequently hides violations in the access to basic rights of these women and their offspring. The argument is structured in two axes, namely: a) critical analysis of the invisibility of women with disabilities and mothers of people with disabilities incarcerated in Brazil in the light of justice as recognition; b) case study on the rights (and violations) of mothers of people with disabilities incarcerated from the Habeas Corpus Coletivo 165.704, which indicates the replacement of provisional by home detention for mothers of children under 12 and of people with disabilities. Framing the situation of these women in terms of justice as recognition reverberates the relational character of justice and, from that, reinforces the necessary discussion on the structuring of our social ethos, which makes us ableists and supporters of a society that punishes people for who they are, not by what they do.

Keywords: Disability; Incarcerated women; Justice as Recognition.

\section{RESUMEN}

Las contradicciones y opresiones invisibles palpitan si prestamos atención a la situación de las mujeres, especialmente de las discapacitadas o madres de discapacitados, en el sistema penitenciario brasileño. El contexto penitenciario reproduce una sociedad sexista, patriarcal y conservadora, excluyendo las especificidades que conforman el universo de las mujeres, ya sea en relación con la orientación sexual, la raza, la edad, la discapacidad, la maternidad, la nacionalidad, etc. A la luz de la justicia como reconocimiento y utilizando la investigación documental y bibliográfica, reflexionamos sobre cómo el olvido de la diversidad de experiencias de reconocimiento vulnera las identidades y niega derechos básicos a las mujeres encarceladas con discapacidad, así como a las madres encarceladas de personas con discapacidad. Nuestro objetivo fue investigar si existe una falta de reconocimiento de estas mujeres expresada por la precariedad de los datos, estudios e indicadores, que en consecuencia esconde violaciones en el acceso a los derechos básicos de estas mujeres y de su descendencia. El argumento está estructurado en dos ejes, a saber: a) un análisis crítico de la invisibilidad de los estudios sobre las mujeres con discapacidad y las madres encarceladas de personas con discapacidad en Brasil a la luz de la justicia como reconocimiento; b) un estudio de caso sobre los derechos (y las violaciones) de las madres encarceladas de personas con discapacidad con base en el Colectivo Habeas Corpus 165.704, que señala la sustitución de la prisión preventiva por la prisión domiciliaria de las madres de niños menores de 12 años y de personas con 
http://dx.doi.org/10.5902/1984686X67647

discapacidad. Enmarcar la situación de estas mujeres en términos de justicia como reconocimiento revierte el carácter relacional de la justicia y, a partir de ahí, refuerza esta necesaria discusión sobre la estructuración de nuestro ethos social, que nos hace capacitadores y legitimadores de una sociedad que castiga a las personas por lo que son, no por lo que hacen.

Palabras clave: Discapacidad; Encarcelamiento femenino; Justicia como reconocimiento.

\section{Introdução}

Reverberam fortemente os ecos do racismo, do machismo, do patriarcado, do sexismo, do capacitismo e do neoconservadorismo em nosso país e, como estratégia encampada neste artigo, fazemos pulsar acelerada e descompassadamente a necessidade de refletirmos sobre justiça e inclusão, com foco nos direitos (e violações) de pessoas com deficiência, pontualmente das encarceradas com deficiência e das encarceradas mães de pessoas com deficiência, condenadas por crimes de menor potencial ofensivo. Afinal, quem são estas mulheres? Por que os estudos, dados e indicadores parecem as invisibilizar? Que direitos Ihes são negligenciados e às suas filhas e filhos? Por que a maioria de nós nem sequer as reconhece como sujeitos de direitos?

Não obstante, tantos questionamentos que se avolumam ao longo deste texto, ressaltamos que nosso objetivo geral é investigar se há ausência de reconhecimento destas mulheres expressa pela precariedade de dados, estudos e indicadores, a ocultar, por consequência, violações no acesso à direitos básicos destas e de sua prole. Em síntese, o problema desta pesquisa é: "há ausência de reconhecimento de mulheres encarceradas com deficiência e de mulheres mães de pessoas com deficiência pelos dados, estudos e indicadores, o que também leva a violações no acesso destas mulheres e de sua prole à direitos básicos?". Neste sentido, para fundamentarmos o conceito de reconhecimento, utilizamo-nos da acepção bidimensional de justiça proposta por Nancy Fraser (FRASER, 2001) (FRASER, 2002) (FRASER, 2007) (FRASER, 2009) (FRASER, 2000) e, ainda, gestamos reflexões, ainda embrionárias, à luz do legado de Ângela Davis sobre justiça, interseccionalidade e encarceramento, especialmente a partir de sua obra "Estarão as prisões obsoletas?" (DAVIS, 2018), reforçando o necessário compromisso acadêmico com o debate sobre os muitos danos irreparáveis causados às vítimas do racismo e do colonialismo ao serem categorizadas como seres humanos inferiores (FANON, 2008) e que persistem em nos assombrar. 
http://dx.doi.org/10.5902/1984686X67647

O pensamento de Nancy Fraser mescla feminismo, teoria crítica e outras perspectivas teóricas, voltando-se para, dentre outros temas, discutir a justiça em um plano bidimensional (reconhecimento e redistribuição), movimentos sociais e para fazer críticas ao capitalismo. Em "Feminismo para os 99\%: um manifesto" (FRASER, ARUZZA e BHATTACHARYA, 2019), explicita-se que o gênero não pode ser isolado de outros marcadores sociais, comprometendo-se também com uma agenda anticapacitista, antirracista, anti-colonizadora, etc. Neste ponto, a aproximamos de Ângela Davis que preenche um vazio deixado por Fraser ao trazer à pauta do feminismo a necessidade de o pensarmos a partir da interseccionalidade e da decolonialidade, especialmente nos deslocando para enfocarmos a questão racial marcadamente negligenciada pelos feminismos ao longo da história, mas maciçamente representada na cor das pessoas encarceradas e negligenciadas dentro de uma estrutura social fortemente racista. Diz-nos Angela Davis:

A prisão funciona, portanto, ideologicamente como um local abstrato em que os indesejáveis são depositados, aliviando-nos da responsabilidade de pensar sobre as verdadeiras questões que afligem as comunidades de que os presos são tirados em números tão desproporcionais. Este é o trabalho ideológico que a prisão realiza - nos livra da responsabilidade de nos engajarmos seriamente nos problemas da nossa sociedade, especialmente os produzidos pelo racismo e, cada vez mais, pelo capitalismo global. (DAVIS, 2018, p. 16)

No Brasil endossamos com grande naturalidade uma espécie de acordo social sobre a necessidade de encarceramento de pessoas que cometem crimes, independentemente da gravidade dos mesmos e menos ainda nos ocupamos com uma reflexão mais consistente sobre a complexidade que envolve criminalização e cárcere. Angela Davis (DAVIS, 2018) nos convida a revermos nossas próprias suposições sobre o encarceramento. A autora faz uma incursão histórica imprescindível, mesmo que não sobre o contexto brasileiro em particular, sobre a prisão como principal forma de punição e desvela a construção de um sistema prisional seletivo em que a punibilidade reproduz formas de escravismo e violência pontual e nos alerta que há, nos EUA, mais chances de pessoas negras, latinas e indígenas irem para a prisão do que irem para as escolas. Ainda hoje, estamos muito distantes disto em nosso país?

Por que nos sentimos mais protegidos/as e seguros/as em havendo cada vez mais prisões e até nem conseguimos mais ver nossas vidas sem elas?, nos perguntaria Davis. As políticas repressivas de segurança e condenações ao cárcere são direcionadas, com grande violência, à população negra, reproduzindo o que ocorria na escravidão (DAVIS, 
http://dx.doi.org/10.5902/1984686X67647

2018). Outra questão pouco presente neste debate é a atenção às demandas de grupos específicos privados de liberdade (mulheres, LGBTQIA+, indígenas, estrangeiros, pessoas com deficiências, etc.) numa dimensão interseccional. Neste sentido, objetivamos problematizar a ausência (ou precariedade) de informações sobre encarceradas com deficiência e sobre as encarceradas mães de pessoas com deficiência e, com isto, apontamos para a necessidade de refletirmos sobre a paridade de participação das mulheres nos espaços institucionais que salvaguardam direitos básicos como uma questão de justiça.

O que é "ser mulher"? Qual o "lugar" da mulher na sociedade? Qual mulher, aliás? Será possível pensar uma "mulher abstrata"? Mulher com deficiência, trans, negra, indígena, mãe, um sem fim de combinações possíveis... Dentre tantas, não haverá uma essência a todas? Por que enfocarmos as encarceradas com deficiência, as encarceradas mães de pessoas com deficiência e suas/seus filhas/os? Perguntas inquietantes que se acumulam nas sombras de nossa alma e são exatamente respostas a elas que nos desafiam, nos confrontam com o que entendemos e vivemos como humanas/os. Respostas que reverberam o tratamento desumano legado às mulheres ao longo da história e que as unidades prisionais reproduzem como se o tempo retrocedesse à ldade Média, ou antes. O sistema prisional é o termômetro que nos faz entender que não são "mulheres em geral" que ocupam as celas das nossas prisões. A maior parcela de mulheres encarceradas são jovens, negras, mães solo e sem estudo. Legado de violências sociais persistentes, não?

Trata-se de uma discussão fugidia da nossa formação, quer familiar ou escolar. Pensar a respeito, trazer o tema para os espaços da vida privada e pública é, pois, fundamental rumo ao processo de mudança social, indispensável à nossa própria sobrevivência enquanto humanidade. A exclusão social, marcadamente manifesta nos ambientes escolares, passa pela reprodução de estereótipos que são socialmente aprendidos e reproduzidos, sob a forma de bullying e outras formas de violência física ou não-física. É a reprodução de discursos capacitistas, machistas, racistas, xenófobos, sexistas, etc. Discursos que atravessam a formação das crianças, mas que também estiveram presentes na formação de profissionais da educação e na de tantas pessoas que circundam o universo escolar. Fugir da existência deste enviesamento formativo não o torna inexistente. Na escola, idealmente, chegarão as/os filhas/os, com deficiência ou não, destas mulheres encarceradas. Na escola chegarão familiares destas mulheres 
http://dx.doi.org/10.5902/1984686X67647

encarceradas. Na escola, se não chegaram, deveriam ter chegado essas próprias mulheres que passaram a cometer crimes. Na escola chegam, chegaram e chegarão muitas/os filhas/os de violências sociais. Por que isto não nos incomoda? De que inclusão social (e escolar) se trata? Aonde estão os estudos sobre isto? Por que ignoramos e nos convencemos de que alguns atravessamentos discursivos e vivenciais não são legítimos, não são parte do mundo que comodamente ocupamos, acriticamente?

\section{Metodologia}

Utilizamos como método a revisão narrativa de literatura, ou seja, estruturamos uma visão panorâmica sobre a temática a partir de pesquisa bibliográfica e de pesquisa documental, sem a pretensão de esgotarmos os resultados apresentados. Ocupamo-nos com duas perguntas que nos inquietam: Há ausência de informações específicas sobre as mulheres com deficiência e sobre as mulheres mães de pessoas com deficiência que se encontram no nosso sistema carcerário? Esta eventual falta de reconhecimento implica também na precariedade de acesso destas mulheres e de sua prole à direitos básicos, como à educação, por exemplo?

A pesquisa bibliográfica foi realizada em duas etapas distintas. Primeiramente, realizamos um mapeamento do campo de interesse através de busca nas seguintes bases eletrônicas: Portal de Periódicos da CAPES e Biblioteca Digital Brasileira de Teses e Dissertações - BDTD. A busca foi realizada utilizando conectores booleanos e combinando as seguintes palavras-chave encarceramento, prisão, cárcere, mulheres, deficiência e interseccionalidade. As combinações foram realizadas como se segue: a) encarceramento OR prisão OR cárcere AND mulheres AND deficiência; b) encarceramento OR prisão OR cárcere AND mulheres AND interseccionalidade.

Nosso marco temporal inicial foi o ano da promulgação da atual Constituição da República Federativa do Brasil, de 1988. A compilação e análise dos dados foram realizadas entre os meses de agosto e setembro de 2021. Foram consideradas as dissertações e teses publicadas, em português, de 1988 a 2021, e artigos científicos publicados, em português, no mesmo período, em periódicos revisados por pares. A busca resultou em 79 fontes, sendo 76 no Portal de Periódicos da CAPES e 03 (três) na BDTD. Após a leitura das fontes, identificamos 07 (sete) no Portal de Periódicos da CAPES e 01 (uma) na BDTD inclinadas ao escopo temático deste artigo. Destas oito, selecionamos 04 (quatro) como as mais relevantes para fundamentação de nossa 
http://dx.doi.org/10.5902/1984686X67647

argumentação. Como critério, nos restringimos às produções que faziam uma análise crítica do encarceramento feminino e/ou utilizavam-se da perspectiva interseccional em sua argumentação, ainda que não propriamente enfocando a deficiência como categoria.

Em seguida, por critério de afinidade teórica, buscamos justificar a necessidade de preenchimento desta lacuna na produção redirecionando a discussão em termos de reparação de injustiças a partir do legado de Nancy Fraser ${ }^{1}$. A pesquisa documental, por sua vez, foi realizada a partir da análise do relatório do Ministro Gilmar Mendes, do Supremo Tribunal Federal, quanto ao Habeas Corpus Coletivo 165.704. Não nos ocupamos com uma análise processual do documento, o tomamos como referência pragmática para ratificarmos os impactos injustos que a falta de reconhecimento das especificidades de encarceradas cuidadoras de pessoas com deficiência tem, ao estender-se a pena restritiva de liberdade para além de sentenças judiciais e da pessoa de seus/suas sentenciados/as.

\section{Desenvolvimento}

\section{Eixo 1. Garimpando fontes como ponto de partida}

Incipientes, sobretudo qualitativamente, parecem ser os dados e indicadores sobre o encarceramento de mulheres com deficiência e de mães de pessoas com deficiência no Brasil. Este vácuo de informações sinaliza, então, que tais mulheres não cometem delitos, especialmente os de menor potencial ofensivo? Ou talvez que estas encarceradas com deficiência ou encarceradas mães de pessoas com deficiência não demandem tratamento específico em relação às demais mulheres em situação de cárcere?

Compilando dados de 2016 do INFOPEN Mulheres e de 2018 da Fundação Santa Cabrini, o infográfico "Depois da Prisão - caminhos possíveis para mulheres", organizado por Dandara Tinoco e Ana Paula Pellegrino, do Instituto Igarapé (TINOCO e PELLEGRINO, 2019), quantifica 42.355 mulheres presas no Brasil, sendo 2.254 delas no estado do Rio de Janeiro. Como podemos verificar abaixo, o documento faz recortes interessantes sobre as especificidades destas mulheres e aponta que, em sua maioria são jovens, negras, com filhos e sem estudo, mas não explicita o quantitativo de mulheres com deficiência nem o quantitativo de mulheres com filhos/as com deficiência: 
http://dx.doi.org/10.5902/1984686X67647

Tabela 1 - Perfil das Mulheres Encarceradas no Brasil

\begin{tabular}{|c|c|c|}
\hline QUEM SÃO AS MULHERES PRESAS? & BRASIL & RIO DE JANEIRO \\
\hline Jovens de 18 a 29 anos & $50 \%$ & $45 \%$ \\
\hline Negras & $62 \%$ & $65 \%$ \\
\hline Com filhos & $74 \%$ & Não informado \\
\hline Solteiras & $62 \%$ & $86 \%$ \\
\hline Ensino Fundamental incompleto & $45 \%$ & $58 \%$ \\
\hline
\end{tabular}

Fonte: Adaptação do Infográfico "Depois da Prisão - caminhos possíveis para as mulheres" (TINOCO e PELLEGRINO, 2019)

Marcadores sociais pulsam deste gráfico para corroborar as disparidades que caracterizam nosso país, especialmente quanto ao acesso ao sistema educacional, marcadamente seletivo e excludente. Muitas mulheres, inclusive, vão sofrer os impactos combinados do sexismo e do racismo, do sexismo e do capacitismo, dentre tantas outras possibilidades. A negligência no enfrentamento a esta questão faz parte de um projeto de sociedade que encampa a perpetuação de hierarquias sociais e econômicas injustas. Precisamos romper com este ciclo focalizado de injustiças.

Dorothy Robertz (ROBERTS, 2012) em interessante análise sobre o encarceramento de mulheres negras pobres nos Estados Unidos, argumenta sobre os impactos que o encarceramento materno tem sobre a vida das crianças, conduzindo-as a riscos e privações. A autora investiga como funcionam os mecanismos estatais de vigilância e punição que tornam as mulheres culpadas pelas suas próprias posições de desvantagem, naturalizando as desigualdades culturais e econômicas e, assim, obscurecendo a necessidade de mudanças sociais. Robertz aponta uma realidade norteamericana que não é tão distante da nossa brasileira: os marcadores de raça, sexo e classe são violentamente expressos em ambos os sistemas prisionais, penalizando desproporcionalmente mulheres negras e pobres, particularmente as mães e cuidadoras.

No Brasil, as estatísticas corroboram uma seletividade do sistema carcerário, que perpetua desigualdades sociais, combinadas ou isoladas. Dados do DEPEN (BRASIL, 2018) sobre as unidades prisionais brasileiras de maneira geral apontam para a alarmante situação de falta de acessibilidade destes espaços para a inserção digna de pessoas com deficiência. Os levantamentos nacionais sobre o perfil sociodemográfico da população feminina encarcerada categorizam faixa etária, etnia, escolaridade, estado civil, entre outros, mas não há detalhamento sobre o perfil das encarceradas com deficiência e o quantitativo de encarceradas que são mães de pessoas com deficiência. 
Segundo Robertz (ROBERTS, 2012), nos EUA há um aumento do número de mulheres negras por crimes envolvendo drogas. E, de modo similar no Brasil, a maioria destas mulheres parece ter na prisão o desfecho para as múltiplas violências que sofrem em suas vidas, desde violência doméstica, abusos físicos e não-físicos, toxicodependência, desemprego ou empregos precarizados, falta de acesso ou acesso inadequado a recursos de saúde, entre outros. Nos EUA, a maioria destas mulheres, segundo Robertz, são mães e estão encarceradas por delitos não violentos. Países diferentes com situações carcerárias semelhantes em relação às mulheres, o que nos sugere a necessidade de ainda refletirmos sobre os impactos que as políticas neoliberais têm no fomento às desigualdades culturais e econômicas de grande parte destas mulheres que passam a compor a população carcerária. Se mães, há graves impactos psicológicos para as crianças que, dentre outros, precisarão gerir os impactos do estigma do encarceramento de suas cuidadoras e, por vezes, passarão a cumprir com elas as penas que lhes foram impostas.

No Brasil, a Nota Técnica no 83/2020/DIAMGE/CGCAP/DIRPP/DEPEN/MJ, da Divisão de Atenção às Mulheres e Grupos Específicos da Coordenação-Geral de Cidadania e Alternavas Penais da Diretoria de Polícias Penitenciárias do Departamento Penitenciário Nacional, informa que são 5.995 homens com deficiência, o que corresponde a $0,83 \%$ do total de presos masculinos, e 385 mulheres com deficiência, que equivalem a $1,04 \%$ do total de presas no país. Os dados gerados não fazem menção às mães de pessoas com deficiência e, tampouco, há uma análise interseccional destas pessoas com deficiência. A categorização busca atender às nomenclaturas indicadas no Estatuto da Pessoa com Deficiência (BRASIL, 2015), a saber: deficiência física, deficiência intelectual, deficiência auditiva, deficiência visual e deficiências múltiplas. $O$ documento traz recomendações para que os estabelecimentos prisionais se ajustem a fim de atender às pessoas com deficiências, dentre os quais destacamos: 
http://dx.doi.org/10.5902/1984686X67647

O tema educação consta como dever do Estado a ser efetivado como direito da população com deficiência, estando presente no Capítulo IV do Estatuto da Pessoa com Deficiência. Nesse capítulo, vale o destaque à proposição presente no caput do art. 27 que assevera: " A educação constitui direito da pessoa com deficiência, assegurados sistema educacional inclusivo em todos os níveis e aprendizado ao longo de toda a vida, de forma a alcançar o máximo desenvolvimento possível de seus talentos e habilidades físicas, sensoriais, intelectuais e sociais, segundo suas características, interesses e necessidades de aprendizagem". (BRASIL, 2020, p. 10)

(...) é necessário promover o acesso das pessoas presas, sejam elas deficientes físicas ou visuais, aos ambientes onde acontecem as aulas, podendo a administração acionar a colaboração de outra pessoa presa, também estudante. Importante ressaltar que toda e qualquer pessoa deficiente, seja intelectual, física, auditiva, visual ou múltipla, possui direito ao acesso à educação. (BRASIL, 2020, p. 10)

Na mesma esteira, é necessário promover o acesso das pessoas presas, sejam elas deficientes intelectuais, físicas, auditivas ou visuais ou múltiplas, às bibliotecas ou locais onde são disponibilizados livros com fito à remição através da leitura. Para os deficientes visuais, a título de exemplo, é possível solicitar doação de livros em braille, falados e digitais acessíveis, às instituições governamentais, não governamentais ou religiosas. (BRASIL, 2020, p. 10)

Destacamos o caráter precário a que o próprio documento faz referência quanto a garantir a educação especial nos estabelecimentos prisionais às pessoas com deficiência encarceradas de modo geral. Pontualmente, sinalizamos a irrisória literatura encontrada a se aprofundar especificamente sobre a situação das mulheres encarceradas quando estas possuem deficiência ou quando são mães e/ou cuidadoras de pessoas com deficiências. Para corroborar esta afirmação, realizamos um mapeamento de fontes sobre o campo investigado neste artigo utilizando operadores booleanos para combinação das palavraschave encarceramento, prisão, cárcere, mulheres, deficiência e interseccionalidade. O período analisado foi de 1988 a 2021 e o critério foi o mesmo para as seguintes bases de dados: Portal de Periódicos da CAPES e Biblioteca Digital Brasileira de Teses e Dissertações.

Combinadas as palavras-chave a partir do uso de operadores booleanos, foram encontradas 76 fontes, em português, espanhol e inglês sobre a realidade brasileira, no Portal de Periódicos da CAPES. Destas, após a leitura de títulos e resumos, foram identificadas apenas 07 (sete) fontes que se aproximavam do tema, mas nenhuma que efetivamente tratava do mesmo, ou seja, apenas 07 (sete) produções analisavam mulheres em situação de cárcere, ainda que nenhuma delas com foco em encarceradas com deficiência ou em encarceradas com filhos/as com deficiência, o que podemos visualizar com a tabela abaixo: 
http://dx.doi.org/10.5902/1984686X67647

Quadro 1 - Fontes com as seguintes combinações de palavras-chave: "encarceramento" OR "prisão" OR "cárcere" AND "interseccionalidade" OR "mulheres" AND deficiência" / Base: Portal de Periódicos da CAPES

(continua)

\begin{tabular}{|c|c|c|c|c|}
\hline TÍTULO & AUTORIA & ANO & RESUMO & NATUREZA \\
\hline $\begin{array}{c}\text { Entre a } \\
\text { soberania da } \\
\text { lei e o chão } \\
\text { da prisão: a } \\
\text { maternidade } \\
\text { encarcerada }\end{array}$ & $\begin{array}{c}\text { Ana } \\
\text { Gabriela } \\
\text { Mendes } \\
\text { Braga }\end{array}$ & 2015 & $\begin{array}{l}\text { A criminosa e a mãe ocupam lugares opostos no } \\
\text { repertório de papéis designados às mulheres na nossa } \\
\text { sociedade. A partir de cinco micronarrativas de } \\
\text { mulheres encarceradas no Brasil, pretende-se } \\
\text { problematizar o exercício da maternidade na prisão e o } \\
\text { lugar da "mãe criminosa" no sistema de justiça. As } \\
\text { estórias aqui narradas são frutos da pesquisa "Dar à luz } \\
\text { na sombra", que teve como objetivo identificar } \\
\text { necessidades e entraves para o exercício dos direitos } \\
\text { maternos de mulheres em situação de prisão. Para } \\
\text { tanto, foi utilizada a pesquisa empírica de abordagem } \\
\text { qualitativa, com combinação das técnicas de } \\
\text { entrevistas, grupo focal, visita in loco, somadas à } \\
\text { pesquisa legislativa e bibliográfica. Ao final, serão } \\
\text { discutidas as estratégias, problemáticas e } \\
\text { consequências que envolvem a defesa de direito das } \\
\text { mulheres e a luta do movimento feminista em relação } \\
\text { ao sistema de justiça criminal. Por fim, serão elencadas } \\
\text { algumas pautas importantes de pesquisa para a } \\
\text { continuidade do presente debate. }\end{array}$ & Artigo \\
\hline $\begin{array}{c}\text { Criminologia } \\
\text { Crítica, } \\
\text { Feminismo e } \\
\text { Intersecciona } \\
\text { lidade na } \\
\text { Abordagem } \\
\text { do Aumento } \\
\text { do } \\
\text { Encarcerame } \\
\text { nto Feminino }\end{array}$ & $\begin{array}{c}\text { Idilva } \\
\text { Maria } \\
\text { Pires } \\
\text { Germano, } \\
\text { Rebeca } \\
\text { Áurea } \\
\text { Ferreira } \\
\text { Gomes } \\
\text { Monteiro } \\
\text { e Mariana } \\
\text { Tavares } \\
\text { Cavalcanti } \\
\text { Liberato }\end{array}$ & 2018 & $\begin{array}{l}\text { Desde } 2000 \text { a população carcerária feminina no Brasil } \\
\text { vem crescendo em ritmo preocupante, lotando as } \\
\text { prisões em todos os estados da Federação. Este } \\
\text { trabalho discute a criminalização de mulheres a partir } \\
\text { de uma ótica interseccional, realçando a intersecção de } \\
\text { gênero, raça-etnia, pobreza e outras fontes de } \\
\text { subordinação como central para entender e enfrentar o } \\
\text { problema. Foram analisadas taxas de encarceramento } \\
\text { e o perfil sociodemográfico da população carcerária } \\
\text { feminina no país e na América Latina, divulgadas em } \\
\text { documentos públicos oficiais. Os dados foram } \\
\text { interpretados a partir de princípios da criminologia } \\
\text { crítica feminista e do pensamento interseccional e à luz } \\
\text { de uma literatura crítica nacional e internacional sobre a } \\
\text { criminalização e o encarceramento em massa, } \\
\text { especialmente de mulheres jovens, negras e pobres. } \\
\text { Feminização da pobreza, discriminação racial e de } \\
\text { gênero, política de guerra às drogas, inchação do } \\
\text { Estado Penal entre outros fatores interligam-se e } \\
\text { resultam no encarceramento seletivo de jovens entre } 18 \\
\text { a } 33 \text { anos, declaradas negras ou pardas, com ensino } \\
\text { fundamental incompleto, respondendo por tráfico de } \\
\text { drogas (flagradas com pequena quantidade de drogas), } \\
\text { mães solteiras. Nosso argumento é que a perspectiva } \\
\text { da interseccionalidade permite superar a análise } \\
\text { descritiva e estanque dos fatores envolvidos em crimes } \\
\text { cometidos por mulheres e seu consequente } \\
\text { encarceramento, esclarecendo como o sistema penal } \\
\text { pode incorporar e perpetuar formas naturalizadas de } \\
\text { controle dos corpos femininos e a injustiça social. } \\
\text { Concluímos que o olhar interseccional ilumina as } \\
\text { complexas situações biográficas e vivências cotidianas } \\
\text { de opressão que afetam cerca de } 45 \text { mil mulheres em } \\
\text { prisões brasileiras hoje. }\end{array}$ & Artigo \\
\hline
\end{tabular}


http://dx.doi.org/10.5902/1984686X67647

Quadro 1 - Fontes com as seguintes combinações de palavras-chave: "encarceramento" OR "prisão" OR "cárcere" AND "interseccionalidade" OR "mulheres" AND deficiência" / Base: Portal de Periódicos da CAPES

(continua)

\begin{tabular}{|c|c|c|c|c|}
\hline TÍTULO & AUTORIA & ANO & RESUMO & NATUREZA \\
\hline $\begin{array}{l}\text { Infopen } \\
\text { Mulheres de } \\
2014 \text { e 2018: } \\
\text { Desafios } \\
\text { para a } \\
\text { Pesquisa em } \\
\text { Psicologia }\end{array}$ & $\begin{array}{c}\text { Ramon } \\
\text { Luis de } \\
\text { Santana } \\
\text { Alcântara, } \\
\text { Carla } \\
\text { Priscilla } \\
\text { Castro } \\
\text { Sousa e } \\
\text { Thaís } \\
\text { Stephanie } \\
\text { Matos } \\
\text { Silva }\end{array}$ & 2018 & $\begin{array}{l}\text { O sistema penitenciário funciona como um ponto de } \\
\text { reflexão de várias questões históricas inerentes à } \\
\text { formação da sociedade brasileira. Uma dessas } \\
\text { questões se refere aos modos patriarcais que foram } \\
\text { estabelecidas as relações de gênero no país. Nesse } \\
\text { sentido, a partir da relevância desta realidade, há a } \\
\text { necessidade de a Psicologia investigar o sistema } \\
\text { prisional feminino sob a luz da produção teórica acerca } \\
\text { das relações de gênero. Este estudo objetiva analisar } \\
\text { comparativamente os Levantamentos Nacionais de } \\
\text { Informações Penitenciárias Mulheres (Infopen } \\
\text { Mulheres) de } 2014 \text { e } 2018 \text { com a finalidade de mapear } \\
\text { e problematizar questões e desafios pertinentes à } \\
\text { pesquisa psicológica. Para tal, utilizam-se como } \\
\text { métodos a análise documental, como recurso válido } \\
\text { para a investigação com dispositivos públicos, e o } \\
\text { ensaio teórico, como uma prática de análise que busca } \\
\text { desvelar novos saberes sobre uma dada realidade. } \\
\text { Pontua-se que há um contexto no sistema prisional } \\
\text { feminino marcado pelo agravamento dos problemas } \\
\text { crônicos comuns ao masculino, em decorrência da } \\
\text { invisibilidade das especificidades femininas. Destaca } \\
\text { que o perfil das mulheres apenadas se constrói como } \\
\text { uma questão interseccional, pois a grande maioria é } \\
\text { constituída por negras, pobres, mães solteiras, que } \\
\text { entraram no crime através de funções subalternas no } \\
\text { tráfico. Problematiza-se que os atenuantes da vida } \\
\text { prisional, como o desenvolvimento educacional e as } \\
\text { atividades laborais, são subaproveitados, articulando } \\
\text { esse problema a repercussões na dimensão psicológica } \\
\text { das apenadas. Por fim, aponta-se que os Infopen } \\
\text { revelam vários desafios para a pesquisa em psicologia, } \\
\text { suscitando que a comunidade científica possa } \\
\text { desenvolver novas pesquisas nesse campo de atuação } \\
\text { e investigação. }\end{array}$ & \\
\hline $\begin{array}{l}\text { "Podem os } \\
\text { privilegiados } \\
\text { escutar?": } \\
\text { provocações } \\
\text { dos } \\
\text { feminismos } \\
\text { marginais à } \\
\text { crítica } \\
\text { criminológica }\end{array}$ & $\begin{array}{c}\text { Mailô de } \\
\text { Menezes } \\
\text { Vieira } \\
\text { Andrade }\end{array}$ & 2020 & $\begin{array}{l}\text { Neste artigo, questiono como podemos, entre privilégios } \\
\text { e opressões, escutar vozes que ecoam da } \\
\text { marginalidade, seus anseios e demandas diante do } \\
\text { aparato penal. Recorrendo às implicações } \\
\text { epistemológicas da perspectiva do ponto de vista } \\
\text { feminista, tensiono os paradoxos entre o saber } \\
\text { criminológico e o feminista no país, com objetivo de } \\
\text { avançar na crítica interseccional e possibilitar caminhos } \\
\text { de escuta ativa de pesquisadoras/es e atores do } \\
\text { sistema de justiça criminal }\end{array}$ & Artigo \\
\hline $\begin{array}{c}\text { Supremo } \\
\text { Tribunal } \\
\text { Federal e a } \\
\text { naturalização } \\
\text { da barbárie }\end{array}$ & $\begin{array}{c}\text { Ana } \\
\text { Flauzina e } \\
\text { Thula } \\
\text { Pires }\end{array}$ & 2020 & $\begin{array}{l}\text { O artigo objetiva explicitar o vocabulário jurídico-político } \\
\text { que informa as decisões do Supremo Tribunal Federal } \\
\text { sobre a questão prisional, atribuindo destaque às } \\
\text { hierarquias de raça, gênero, classe e sexualidade. } \\
\text { Busca-se evidenciar a sua atuação na reprodução do } \\
\text { genocídio negro com impactos decisivos para as } \\
\text { mulheres, em especial como um órgão chancelador da } \\
\text { barbárie instalada no sistema de justiça criminal. }\end{array}$ & Artigo \\
\hline
\end{tabular}


http://dx.doi.org/10.5902/1984686X67647

Quadro 1 - Fontes com as seguintes combinações de palavras-chave: "encarceramento" OR "prisão" OR "cárcere" AND "interseccionalidade" OR "mulheres" AND deficiência" / Base: Portal de Periódicos da CAPES

(conclusão)

\begin{tabular}{|c|c|c|c|c|}
\hline TÍTULO & AUTORIA & ANO & RESUMO & NATUREZA \\
\hline $\begin{array}{c}\text { Sistema } \\
\text { Carcerário } \\
\text { Feminino: } \\
\text { uma análise } \\
\text { das políticas } \\
\text { públicas de } \\
\text { segurança } \\
\text { com base em } \\
\text { um estudo } \\
\text { local }\end{array}$ & $\begin{array}{c}\text { Bruna } \\
\text { Rios } \\
\text { Martins } \\
\text { Santos e } \\
\text { Vânia } \\
\text { Aparecida } \\
\text { Rezende }\end{array}$ & 2020 & $\begin{array}{l}\text { Embora a taxa de encarceramento feminino tenha } \\
\text { aumentado significativamente nos últimos anos, a } \\
\text { construção de políticas públicas que englobam a } \\
\text { perspectiva de gênero ainda é um processo estatal a } \\
\text { ser consolidado na agenda governamental. Este } \\
\text { trabalho apresenta o estudo de um caso que teve como } \\
\text { locus de investigação o universo carcerário feminino de } \\
\text { uma comarca no estado de Minas Gerais, seu objetivo } \\
\text { foi analisar como a diferença de gênero, na construção } \\
\text { de políticas públicas de segurança no sistema prisional, } \\
\text { influencia as vivências do feminino no cárcere. A } \\
\text { pesquisa, de natureza qualitativa, utilizou entrevistas } \\
\text { com roteiros semiestruturados e análise documental. } \\
\text { Os dados produzidos foram submetidos à análise de } \\
\text { conteúdo proposta por Bardin, cuja categorização } \\
\text { textual ocorreu pela classificação de elementos } \\
\text { constitutivos de um conjunto e reagrupamento com } \\
\text { base em características comuns destes elementos. Por } \\
\text { meio desta análise, foram construídas quatro } \\
\text { categorias: encarceramento e gênero; maternidade e } \\
\text { cárcere; políticas públicas e vivências no cárcere. Os } \\
\text { principais resultados apontam que as especificidades } \\
\text { de gênero no encarceramento feminino influenciam as } \\
\text { vivências produzidas resultantes de vários tipos de } \\
\text { violência que marcam definitivamente a vida das } \\
\text { mulheres, destacando-se a relação com a maternidade, } \\
\text { apontada como a principal fonte de sofrimento. Apesar } \\
\text { de avanços significativos, a inserção da questão de } \\
\text { gênero na formulação das políticas públicas de } \\
\text { segurança pública ainda é recente e incipiente no que } \\
\text { tange às especificidades do cárcere feminino. }\end{array}$ & \\
\hline $\begin{array}{c}\text { Judicializaçã } \\
\text { o do } \\
\text { sofrimento } \\
\text { negra. } \\
\text { Maternidade } \\
\text { negra e fluxo } \\
\text { do Sistema } \\
\text { de Justiça } \\
\text { Criminal no } \\
\text { Rio de } \\
\text { Janeiro }\end{array}$ & $\begin{array}{l}\text { Luciane } \\
\text { O. Rocha }\end{array}$ & 2020 & $\begin{array}{l}\text { Este artigo é baseado em etnografia realizada entre os } \\
\text { anos de } 2015 \text { e } 2017 \text { no Núcleo de Direitos Humanos } \\
\text { da Defensoria Pública do Rio de Janeiro (NUDEDH), } \\
\text { mais especificamente no programa de Proteção às } \\
\text { Vítimas de Violência Praticada por Agentes Estatais ou } \\
\text { Particulares. No contexto de antinegritude vigente no } \\
\text { Rio de Janeiro, esta linha de atuação do NUDEDH se } \\
\text { tornou uma ferramenta utilizada por mães de vítimas de } \\
\text { violência policial em favelas e periferias, que passam a } \\
\text { atuar como assistentes de acusação nos processos } \\
\text { penais dos assassinatos de seus filhos e filhas. Este } \\
\text { artigo, ao mobilizar literatura sobre a Teoria Crítica da } \\
\text { Raça e Estudos Negros, tem por objetivo examinar os } \\
\text { usos do sofrimento negro e da maternidade negra para } \\
\text { a movimentação do Fluxo do Sistema de Justiça } \\
\text { Criminal. }\end{array}$ & Artigo \\
\hline
\end{tabular}

Fonte: Portal de Periódicos da CAPES (disponível em: https://www-periodicos-capes-govbr.ezl.periodicos.capes.gov.br/index.php?). Dados compilados pela autora (2021). 
http://dx.doi.org/10.5902/1984686X67647

Na Biblioteca Digital de Teses e Dissertações foram encontradas 03 (três) fontes nos mesmos critérios acima estabelecidos. Destas, apenas 01 (uma) apresentou afinidade com o escopo temático deste artigo, a saber:

Quadro 2 - Fonte com a seguinte combinação de palavras-chave: "encarceramento" OR "prisão" OR "cárcere" AND "interseccionalidade" OR "mulheres" AND deficiência"

\begin{tabular}{|c|c|c|c|c|}
\hline TÍTULO & AUTORIA & ANO & RESUMO & NATUREZA \\
\hline $\begin{array}{c}\text { À procura de } \\
\text { novos } \\
\text { caminhos: } \\
\text { mulheres } \\
\text { negras e suas } \\
\text { experiências a } \\
\text { partir do sistema } \\
\text { prisional do Rio } \\
\text { de Janeiro }\end{array}$ & $\begin{array}{c}\text { Adriana } \\
\text { Severo } \\
\text { Rodrigues }\end{array}$ & 2010 & $\begin{array}{l}\text { O presente trabalho tem como objetivo } \\
\text { conhecer as experiências vividas pelas } \\
\text { mulheres negras, tentando descobrir se as } \\
\text { mesmas receberam tratamento diferenciado } \\
\text { dentro da prisão em função da questão racial } \\
\text { dos negros. No Brasil nos últimos quatro } \\
\text { anos observamos expressivo crescimento } \\
\text { dos crimes cometidos por mulheres, o que } \\
\text { vem chamando atenção dos estudiosos do } \\
\text { assunto. Além disso, o sistema penitenciário } \\
\text { brasileiro apresenta deficiências estruturais, } \\
\text { que reforçam a cultura da violência } \\
\text { institucional, fomentando práticas e } \\
\text { abordagens discriminatórias e violentas, } \\
\text { ferindo a dignidade e violando direitos. Estas } \\
\text { práticas também ocorrem no } \\
\text { encarceramento feminino e nossa hipótese é } \\
\text { que essas são ainda mais perceptíveis } \\
\text { quando realizado o recorte étnico racial. Esta } \\
\text { realidade revela outra face das } \\
\text { desigualdades sociais e do racismo, o que } \\
\text { pode se acentuar transformando-se em } \\
\text { vulnerabilidades penais quanto ao } \\
\text { cometimento de um delito. Neste contexto o } \\
\text { presente estudo questiona as expressões do } \\
\text { racismo dentro do sistema prisional. O } \\
\text { estudo contou com a contribuição de } 10 \\
\text { mulheres internas e egressas do sistema } \\
\text { prisional do Rio de Janeiro. O resultado do } \\
\text { estudo apresentou que a população negra } \\
\text { do estado do Rio de Janeiro está mais } \\
\text { representada nas prisões do que na } \\
\text { população do Estado. Ainda assim, as } \\
\text { mulheres negras que foram entrevistadas } \\
\text { não reconhecem as expressões do racismo } \\
\text { no interior das prisões. }\end{array}$ & Dissertação \\
\hline
\end{tabular}

Fonte: Base Digital Brasileira de Teses e Dissertações (disponível em: https://bdtd.uftm.edu.br/). Dados compilados pela autora (2021).

Reiteramos que nenhuma das fontes encontradas se ocupava com as especificidades das mulheres com deficiência encarceradas ou das encarceradas mães de pessoas com deficiência, nos sugerindo um vácuo na produção de informações sobre as mesmas. No tocante às mães encarceradas e às mulheres negras encarceradas há alguma produção, como podemos ver, concentrada entre os anos de 2018 e 2020. Reconhecido este 
http://dx.doi.org/10.5902/1984686X67647

obstáculo, destacamos, a seguir, quatro destas referências, posto se inclinarem a uma análise crítica do encarceramento feminino e/ou utilizarem-se da perspectiva interseccional em sua argumentação, ainda que tão tenham se ocupado propriamente da deficiência enquanto categoria.

O texto de Ana Gabriela Mendes Braga (BRAGA, 2015) nos provoca a refletir sobre a maternidade e o cárcere a partir de quatro micronarrativas de mulheres encarceradas, vidas que são negligenciadas nas salas de audiências, mas que muito têm a dizer sobre o ser mulher, o ser mãe e, em sua maioria, sobre o ser pobre e negra no nosso sistema prisional. As narrativas foram obtidas no âmbito do projeto "Dar à luz na sombra: condições atuais e possibilidades futuras para o exercício da maternidade por mulheres em situação de prisão", entre 2013 e 2014, como desdobramento do projeto "Pensando o Direito", fruto de parceria entre a Secretaria de Assuntos Legislativos do Ministério da Justiça e o Instituto de Pesquisa Econômica. A autora faz apontamentos sobre a necessidade de reconhecimento de grupos específicos no sistema prisional e de aprofundamento sobre os mesmos.

No artigo de Idilva Germano, Rebeca Monteiro e Mariana Liberato (GERMANO, MONTEIRO e LIBERATO, 2018), dados são apresentados sobre o perfil sociodemográfico das presidiárias no Brasil e na América Latina corroborando a teoria crítica feminista sobre a seletividade das mulheres encarceradas, cujos direitos são violados ao serem reproduzidas formas de discriminação institucionalizadas. Com isto, indiretamente, o artigo nos reforça a ausência de informações sobre as encarceradas com deficiência bem como sobre as encarceradas mães de pessoas com deficiência. A produção é extremamente interessante por trazer a interseccionalidade como ferramenta analítica e por se configurar num ensaio interpretativo sobre as taxas de encarceramento de mulheres e sobre o perfil sociodemográfico da população carcerária feminina no Brasil e na América Latina. Não traz o recorte de deficiência, mas faz uma incursão sobre a seletividade penal, sobre a feminização da pobreza e sobre a baixa escolarização como um marcador do público encarcerado feminino no nosso país. Reforça também as disparidades ínsitas à Divisão Sexual do Trabalho, que precariza o trabalho da mulher e diminui as chances paritárias de participação econômica das mulheres no mercado de trabalho.

Bruna Santos e Vânia Rezende (SANTOS e REZENDE, 2020) enfatizam também o marcador de gênero no encarceramento feminino na produção de violências e destacam a maternidade como principal fonte de sofrimento. $O$ artigo identifica quatro grandes 
http://dx.doi.org/10.5902/1984686X67647

categorias que materializam a invisibilidade das mulheres no sistema carcerário, a saber: maternidade e cárcere, encarceramento e gênero, vivências no cárcere e políticas públicas. Segundo elas, o tratamento indiferente às mulheres complexifica o processo de ressocialização das mesmas. O texto traz a CRFB/1988 como um marcador importante na garantia de direitos básicos, inclusive reconhecendo a segurança pública como um processo que deve ser articulado institucional e socialmente a fim de que sejam corrigidas disparidades e injustiças. Um dos pontos altos desta produção é exatamente reforçar a importância da participação social para o aperfeiçoamento das políticas de segurança pública e para que seja encampada a discussão de gênero neste âmbito. Sem a participação efetiva das mulheres e o reconhecimento de suas demandas específicas, as políticas públicas de gênero, sobretudo no âmbito do sistema prisional, não serão concretizadas.

Por fim, destacamos a dissertação de Adriana Severo Rodrigues (RODRIGUES, 2010) que, já em 2010, debate as especificidades das mulheres negras no sistema carcerário, enfatizando as inúmeras violências produzidas no âmbito de uma estrutura social marcadamente racista. A partir de relatos destas mulheres, a autora nos alerta para a inadiável necessidade de não apenas mudarmos as instituições prisionais, mas também ressignificarmos o modelo de sociedade que temos e o que queremos ter, desvencilhandonos do atual, fortemente marcado pelo consumismo e ideais neoliberais que excluem e reproduzem injustiças focalizadas. Rodrigues reforça a consciência que as mulheres entrevistadas em sua pesquisa têm quanto aos delitos que cometem, mas que isto não é mais relevante do que o valor que elas atribuem ao bem-estar de suas famílias. Exclusão social, violências impostas por uma sociedade de consumo, insuficiência de rendimentos para subsidiarem a si e a suas famílias e tantos outros fatores reverberam as incongruências injustas que estas mulheres experienciam.

\section{Eixo 2. (In)Justiça e (Falso)Reconhecimento: a paridade de participação como fundamento normativo}

A análise da situação das encarceradas pelas lentes da teoria de justiça de Fraser propõe um modelo de reconhecimento em termos de justiça e não em termos de identidade. Significa que "a justiça requer arranjos sociais que permitam a todos os membros (adultos) da sociedade interagir uns com os outros como parceiros" (FRASER, 2007, p. 118). Neste sentido, Fraser coloca a questão da justiça como reconhecimento (e como redistribuição) 
http://dx.doi.org/10.5902/1984686X67647

nos termos de se defender uma paridade de participação como fundamento normativo, ou seja,

(...) é injusto que, a alguns indivíduos e grupos, seja negada a condição de parceiros integrais na interação social, simplesmente em virtude de padrões institucionalizados de valoração cultural, de cujas construções eles não participaram em condições de igualdade, e os quais depreciam as suas características distintivas ou as características distintivas que lhes são atribuídas. Deve-se dizer que o não reconhecimento é errado porque constitui uma forma de subordinação institucionalizada - e, portanto, uma séria violação da justiça. (FRASER, 2007, p. 112)

O sistema prisional institucionalizou o falso reconhecimento das especificidades das mulheres em geral e menos ainda o faz em relação às mulheres com deficiência e, tampouco, atende às encarceradas com filhos/as com deficiência, inviabilizando-se como espaço de ressocialização e de recuperação social das apenadas. Entendemos ser preciso reparar estes arranjos institucionais injustos a fim de que sejam minimizados os obstáculos à paridade de participação.

Davis (DAVIS, 2018) nos alerta sobre a ausência da análise de gênero no que tange ao sistema prisional e, desta maneira, reforça a existência de unidades prisionais que ignoram as especificidades das mulheres, reproduzindo as agruras de uma sociedade marcadamente racista, machista, sexista e patriarcal, funcionando dentro de padrões hegemônicos de humanidade/desumanidade. Neste artigo, reforçamos especialmente a negligência sobre as demandas das mulheres que possuem deficiência (sobretudo em função de inúmeras barreiras à acessibilidade) bem como as das mães de pessoas com deficiência. Enfatizar o debate sobre elas é também, parafraseando Galeano, adentrar nas veias ainda abertas da democracia brasileira.

O problema do reconhecimento deve ser colocado, pois, como parte de uma estrutura social fragilizada e expropriada por interesses neoliberais, não em termos de identidade ou identificação. Nas palavras de Fraser:

O não reconhecimento (...) significa subordinação social no sentido de ser privado de participar como um igual na vida social. Reparar a injustiça certamente requer uma política de reconhecimento, mas isso não significa mais uma política de identidade. No modelo de status, ao contrário, isso significa uma política que visa a superar a subordinação, fazendo do sujeito falsamente reconhecido um membro integral da sociedade, capaz de participar com os outros membros como igual (FRASER, 2007, p. 108)

No livro "Manifesto para os 99\%" (FRASER, ARUZZA e BHATTACHARYA, 2019), as autoras, donde se inclui Fraser, ao iluminarem a atual crise do capitalismo, reforçam a importância de pensarmos o feminismo a partir de uma necessária luta anticapitalista. Nesta 
http://dx.doi.org/10.5902/1984686X67647

medida, enfatizam que a luta por reconhecimento das diferenças foi substituindo os interesses de classes como fundamento da luta política e da luta por justiça social e, consequentemente, as políticas de identidade passaram a ser marcadores incorporados pelo discurso neoliberal, consolidando-o.

A injustiça contra a mulher é material e simbólica, ou seja, é tanto no plano econômico (marginalização econômica, exploração, precarização e/ou desvalorização do trabalho feminino) quanto no plano cultural (falta de comunicação, falso reconhecimento, desrespeito). Um claro exemplo é o desvalor que as funções laborais desempenhadas pelas mulheres têm, ainda que indispensáveis ao funcionamento do capitalismo. Segundo dados da Pesquisa Nacional de Amostra de Domicílios Contínua (PNAD Contínua), do Instituto Brasileiro de Geografia e Estatística (IBGE), atualizados até 2018, o trabalho doméstico é exercido eminentemente por mulheres, particularmente negras, de baixa escolaridade e famílias pobres (ALCÂNTARA, SOUSA e SILVA, 2018). Dados que sugerem a maternidade como obstáculo cultural, mas também material. Trabalho doméstico desvalorizado e exercido, via de regra, em dupla jornada (na residência de empregadores/as e na própria), com baixa remuneração e sem salvaguardo de direitos trabalhistas. A cadeia que se desdobra no exemplo do trabalho doméstico é perversa e pouco nos ocupamos com as correções das injustiças a ela vinculadas. São inúmeras as situações de mulheres que se ocupam de cuidar de filhos/as de outras pessoas e que deixam a descoberto os cuidados com seus/suas próprios/as filhos/as ou que repassa estes cuidados através da precarização do trabalho de cuidado de outras mulheres. O trabalho doméstico é um exemplo recorrente exatamente por fazer pulsar as disparidades de participação social e tratamento desigual entre trabalho exercido por homens e por mulheres.

Como vimos, a mulher in abstrato não existe, há a mulher negra, branca, não-branca, de classe média, com deficiência, etc. Assim, como Fraser (FRASER, 2009), defendemos um conceito de justiça que possa abarcar tanto reconhecimento quanto redistribuição e, ainda, reenquadramento político. Não se trata de nos direcionarmos para o fomento de políticas de identidade, mas, segundo Fraser (FRASER, ARUZZA e BHATTACHARYA, 2019), é preciso fomentarmos a paridade de participação nos diferentes espaços decisórios. Entendemos que o desequilíbrio da participação da mulher nos espaços perpetua injustiças e gera, inclusive, uma ausência generalizada de dados e informações sobre as especificidades das mesmas. Pensar em termos de políticas que assegurem 
http://dx.doi.org/10.5902/1984686X67647

paridade de participação é pensar em consolidar na prática direitos sociais que só existem na teoria e avançar na correção não apenas das injustiças de gênero, mas também relacionadas à etnia, raça, deficiência, idade, corporidades, etc. Avaliação crítica que urge ser materializada nos espaços escolares, ainda marcadamente reprodutores de exclusão e iniquidade de participação.

\section{Eixo 3. Encarceradas Mães de Pessoas com Deficiência no Brasil: o Habeas Corpus Coletivo 165.704 como lente para a justiça bidimensional de Fraser}

Em 14 de junho de 2021, o Supremo Tribunal de Justiça realizou uma audiência pública para discutir a fiscalização do sistema prisional brasileiro, convocada pelo relator do Habeas Corpus (HC) 165.704, ministro Gilmar Mendes. O referido HC foi examinado em outubro de 2020 e deferido pela Corte, determinando-se a substituição de prisão cautelar por domiciliar de pais e responsáveis por crianças menores de 12 anos e por pessoas com deficiência, consoante requisitos dispostos no artigo 318 do Código de Processo Penal. Longe de uma análise processual sobre o tema, nos debruçamos aqui nos argumentos jurídico-filosóficos sobre o mesmo em termos bastante pontuais, quais sejam, os que se direcionam para a questão dos impactos da ausência de cuidadores/as de pessoas com deficiência, estendendo-se a pena restritiva de liberdade para além de sentenças judiciais e de seus/suas sentenciados/as.

Indiscutível que as mulheres encarceradas possuem especificidades que são ignoradas pelo sistema prisional brasileiro, como aponta o relatório INFOPEN Mulheres (BRASIL, 2018) ao apresentar, em relação às encarceradas com deficiência, que 73,5\% delas estão em unidades que não foram adaptadas para recebê-las. O relatório INFOPEN Mulheres (BRASIL, 2018) reconhece que direitos básicos assegurados pela Lei de Execução Penal (BRASIL, 1984) são violados, como a obrigatoriedade de local adequado para a realização da visita social e da visita íntima, inexistente na maior parte das unidades prisionais no Brasil. Em se tratando de mães, sem fazer distinção das que possuem filhos/as com deficiências, o relatório reconhece que o tratamento desumano é extensivo à sua prole, ao apontar que apenas 48 unidades prisionais no nosso país possuem berçário, creche ou centro de referência materno-infantil, direito também salvaguardado pela Lei de Execução Penal (BRASIL, 1984) que assegura às condenadas cuidar dignamente de seus/suas filhos/as em local adequado, amamentando-os/as até os seis meses de idade. Contudo, na prática, o que os dados do INFOPEN Mulheres (BRASIL, 2018) nos fazem 
http://dx.doi.org/10.5902/1984686X67647

perceber é o acompanhamento pré-natal e assistência à saúde da gestante ou puérpera insatisfatório ou insuficiente, bebês amamentados em ambientes degradantes, ausência de creches ou creches em condições inadequadas, pessoas com deficiência afastadas do convívio de, na maioria das vezes, suas únicas cuidadoras, etc. Situações que, consequentemente, comprometerão, o desenvolvimento, a socialização, a aprendizagem e a saúde mental destas crianças e pessoas com deficiência cujas mães encontram-se encarceradas. Crianças, com deficiência ou não, em idade escolar e jovens, com deficiência ou não, em idade escolar cujas mães cumprem pena privativa de liberdade podem ser vítimas de bullying, ansiedade, depressão, instabilidade emocional, dificuldades de aprendizagem e, consequentemente, se sentirem excluídas da vida social, especialmente no âmbito escolar. A Pesquisa Nacional de Saúde do Escolar - PeNSE (2019) aponta que um em cada dez adolescentes já sofreu violência nas redes sociais, além de trazer outros indicadores que reforçam as inúmeras agressões sofridas por crianças e adolescentes em nosso país, especialmente pelas meninas e pelas jovens.

Um intenso debate se impôs ao longo dos últimos anos e nos direcionou para a argumentação ínsita ao HC visando assegurar o direito de que mães de crianças até doze anos incompletos e mães de pessoas com deficiência tenham suas prisões preventivas convertidas em prisões domiciliares, o que salvaguardaria os direitos de seus filhos/as. Não se trata de afastar a punibilidade das condenadas, mas sim assegurar condições mínimas de dignidade para o exercício da maternagem e da infância.

A conversão da prisão preventiva em domiciliar, enfatize-se, apenas será possível quando se tratarem de mulheres que cometeram crimes de menor potencial ofensivo. Justifica-se, pois a punição para estas situações em nosso país é a restrição da liberdade e de privacidade. Não há no Brasil previsão de pena de morte, de tortura ou de tratamento indigno, ainda mais extensivos à filhos/as das condenadas. Ressalte-se, inclusive, que o tratamento digno à pessoa humana é princípio constitucional preconizado explicitamente

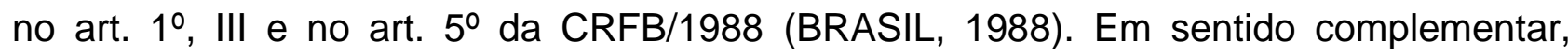
mencione-se o disposto no art. 227 da CRFB/1988 sobre a proteção dos direitos das crianças. Outras normas brasileiras ocuparam-se por reger os direitos das crianças e adolescentes, como o Estatuto da Criança e do Adolescente (BRASIL, 1990), o Estatuto da Primeira Infância (BRASIL, 2016), bem como os direitos das pessoas com deficiência, como o Estatuto da Pessoa com Deficiência (BRASIL, 2015), No plano internacional tantas outras, por exemplo, as Regras de Bangkok (BRASIL, 2016). 
http://dx.doi.org/10.5902/1984686X67647

Pelo exposto, em casos não excepcionais, será ainda questionável a importância de crianças de até doze anos incompletos e pessoas com deficiência conviverem com suas mães? Por que tanta resistência na aplicação dos direitos reconhecidos pelo HC? Em se tratando de mulheres encarceradas, mesmo as que cometem crimes de menor potencial ofensivo, as respostas esbarrarão em outras questões ainda mais complexas, de ordem material e cultural. Isto porque tais mulheres (em suas diferentes experiências e intersecções) são condenadas não apenas pelo que fizeram, mas também por quem são. Muitas delas perdem a condição de sujeito de direitos, perdem o direito de maternarem e perdem até mesmo a natureza humana que lhes deveria render paridade de participação social no mesmo instante em que são conduzidas ao cárcere. $\mathrm{E}$, com elas, o direito à infância de muitas crianças também será injustamente perdido.

\section{Considerações finais}

Neste artigo trouxemos apontamentos quanto à precariedade de informações, dados e indicadores sobre as especificidades das mulheres com deficiência em situação de privação de liberdade e das encarceradas mães de pessoas com deficiência no Brasil. Identificamos que o sistema prisional brasileiro é notadamente seletivo e, em se tratando de mulheres, amplamente direcionado a jovens, negras, sem estudo e mães solo. Em relação ao público feminino, ainda, observamos por dados do INFOPEN Mulheres (BRASIL, 2018) que há violações diuturnamente às Regras de Bangkok (BRASIL, 2016) e à própria Lei de Execução Penal (BRASIL, 1984). É a materialização no sistema prisional de uma sociedade androcêntrica, que não reconhece as especificidades das mulheres e que lhes negligencia direitos básicos. No tocante às mulheres com deficiência e às mães de pessoas com deficiência, reiteramos a necessidade de mais estudos que possam fundamentar políticas públicas direcionadas a este público, reconhecendo suas demandas pontuais e apresentando projetos que estejam em andamento com vistas a garantir o direito à escolarização, inclusive a educação especial na perspectiva da educação inclusiva. Trouxemos o exemplo do Habeas Corpus Coletivo 165.704 (BRASIL, 2021) que reconhece as especificidades destas mulheres, mas ainda segue como desafio que se concretizem os direitos básicos nele reconhecidos na prática social.

Buscamos sinalizar uma das muitas feridas abertas em nossas veias acadêmicas, em tempos em que reproduzimos discursos de ódio que ainda condenam e estigmatizam as mulheres sem uma análise consistente sobre reprodução social como problema. O Brasil é 
reflexo de um mundo onde o trabalho não remunerado das mulheres está na base da sociedade capitalista, mas é menosprezado, subvertido e oneroso desproporcionalmente a mulheres específicas e em contextos bem pontuais. É preciso problematizar os lugares em que as mulheres estão em nossos discursos, inclusive para refletirmos sobre as contingências que levam muitas destas às prisões. Nosso modo de viver segue relegando a segundo plano o cuidado, os afetos e as tarefas femininas, impedindo que tenhamos uma leitura crítica sobre a lógica capitalista, reprodutora de injustiças sociais e, por certo, se não nos revisitarmos enquanto agentes racionais que nos vangloriamos em ser, nossas ações nos conduzirão à degradação do ambiente em que vivemos e à extinção da nossa própria espécie.

\section{Referências}

ALCÂNTARA, R. L. D. S.; SOUSA, C. P. C.; SILVA, T. S. M. Infopen Mulheres de 2014 e 2018: desafios para a pesquisa em Psicologia. Psicologia: Ciência e Profissão [online], Brasília, n. 38, p. 88-101, 2018. Disponivel em: https://doi.org/10.1590/19823703000212154. Acesso em: 07 setembro 2021.

ANDRADE, M. D. M. V. Podem os privilegiados escutar?": provocações dos feminismos marginais à crítica criminológica. Direito e Práxis, v. 11, n. 4, p. 2302-2329, Dezembro 2020. ISSN 2179-8966. Disponivel em: https://www.e-

publicacoes.uerj.br/index.php/revistaceaju/article/view/43476. Acesso em: 19 Dezembro 2021.

BRAGA, A. G. M. Entre a soberania da lei e o chão da prisão: a maternidade encarcerada. Direito GV, v. 11, n. 2, p. 523-546, 2015. ISSN 2317-6172. Disponivel em:

https://www.scielo.br/j/rdgv/a/qHnWZrVyx7xV9DQwr97rdZQ/abstract/?lang=pt\#ModalAr ticles. Acesso em: 19 Dezembro 2021.

BRASIL. Lei de Execução Penal (Lei n. 7.210, de 11 de julho de 1984). Brasília: Presidência da República, 1984. Disponivel em:

http://www.planalto.gov.br/ccivil_03/leis/l7210.htm. Acesso em: 19 Dezembro 2021.

BRASIL. Constituição da República Federativa do Brasil de 1988. Distrito Federal: Presidência da República, 1988. Disponivel em: http://www.planalto.gov.br/ccivil_03/constituicao/constituicao.htm. Acesso em: 19 Dezembro 2021.

BRASIL. Estatuto da Criança e do Adolescente (Lei n. 8.069, de 13 de julho de 1990). Distrito Federal: Presidência da República, 1990. Disponivel em: http://www.planalto.gov.br/ccivil_03/leis/l8069.htm. Acesso em: 19 Dezembro 2021. 
http://dx.doi.org/10.5902/1984686X67647

BRASIL. Lei Brasileira de Inclusão (Lei n. 13.146, de 06 de julho de 2015). Distrito Federal: Presidência da República, 2015. Disponivel em: http://www.planalto.gov.br/ccivil_03/_ato2015-2018/2015/lei/l13146.htm. Acesso em: 19 Dezembro 2021.

BRASIL. Estatuto da Primeira Infância (Lei n. 13.257, de 08 de março de 2016). Distrito Federal: Presidência da República, 2016. Disponivel em:

http://www.planalto.gov.br/ccivil_03/_ato2015-2018/2016/lei/l13257.htm. Acesso em: 19 Dezembro 2021.

BRASIL. Regras de Bangkok: regras das Nações Unidas para o tratamento de mulheres presas e medidas não privativas de liberdade para mulheres infratoras. Distrito Federal: Conselho Nacional de Justiça, 2016. Disponivel em: https://www.cnj.jus.br/wpcontent/uploads/2019/09/cd8bc11ffdcbc397c32eecdc40afbb74.pdf. Acesso em: 19 Dezembro 2021.

BRASIL. Projeto BRA 34/2018: produto 5 relatório temático sobre as mulheres privadas de liberdade, considerando os dados do produto 01, 02, 03 e 04 (Relatório INFOPEN Mulheres). DEPEN/MJ. Brasília. 2018.

BRASIL. NOTA TÉCNICA № 83/2020/DIAMGE/CGCAP/DIRPP/DEPEN/MJ. Distrito Federal: Ministério da Justiça/Divisão de Atenção às Mulheres e Grupos Específicos da Coordenação-Geral de Cidadania e Alternativas Penais da Diretoria de Políticas Penitenciárias do Departamento Penitenciário Nacional, 2020. Disponivel em: https://www.mpma.mp.br/arquivos/CAOPCRIM/nota_tecnica/P_EXECU\%C3\%87\%C3\% 830_PENAL/NOTA_T\%C3\%89CNICA_N\%C2\%BA_83.2020.DIAMGE.CGCAP.DIRPP. DEPEN.MJ.pdf. Acesso em: 19 Dezembro 2021.

BRASIL. Habeas Corpus Coletivo 165.704. Distrito Federal: Supremo Tribunal Federal, 2021. Disponivel em:

https://stf.jusbrasil.com.br/jurisprudencia/1170666157/habeas-corpus-hc-165704-df0006235-6420181000000/inteiro-teor-1170666160. Acesso em: 22 Agosto 2021.

DAVIS, A. Estarão as prisões obsoletas? Rio de Janeiro: Difel, 2018.

FANON, F. Pele negra, máscaras brancas. Bahia: UFBA, 2008.

FLAUZINA, A. L. P.; PIRES, T. R. D. O. Supremo Tribunal Federal e a naturalização da barbárie. Direito e Práxis, Rio de Janeiro, v. 11, n. 2, Junho 2020. ISSN 2179-8966. Disponivel em: https://www.e-

publicacoes.uerj.br/index.php/revistaceaju/article/view/50270. Acesso em: 19 Dezembro 2021.

FRASER, N. Rethinking Recognition. New Left Review, Londres, Reino Unido, n. 3, 2000. Disponivel em: https://newleftreview.org/issues/ii3/articles/nancy-fraserrethinking-recognition. Acesso em: 22 Agosto 2021.

FRASER, N. Da redistribuição ao reconhecimento? Dilemas da justiça da era póssocialista. In: SOUZA, J. Democracia hoje. Brasília: UNB, 2001. 
FRASER, N. Políticas feministas na era do reconhecimento: uma abordagem bidimensional da justiça de gênero. In: CRISTINA BRUSCHINI, S. U. Gênero, Democracia e Sociedade Brasileira. São Paulo: Editora 34, 2002.

FRASER, N. Reconhecimento sem Ética. Lua Nova: Revista de Cultura e Política, São Paulo, n. 70, 2007. Disponivel em:

https://www.scielo.br/j/In/a/JwvFBqdKJnvndHhSH6C5ngr/?format=pdf\&lang=pt. Acesso em: 22 Agosto 2021.

FRASER, N. Reenquadrando política em um mundo globalizado. Lua Nova: Revista de Cultura e Política [online], São Paulo, v. 77, p. 11-39, 2009. ISSN 1807-0175. Disponivel em: https://www.scielo.br/j/In/a/BJjZvbgHXyxwYKHyJbTYCnn/abstract/?lang=pt\#. Acesso em: 22 Agosto 2021.

FRASER, N.; ARUZZA, C.; BHATTACHARYA, T. Feminismo para os 99\%: um manifesto. São Paulo: Boitempo, 2019.

GERMANO, I. M. P.; MONTEIRO, R. Á. F. G.; LIBERATO, M. T. C. Criminologia Crítica, Feminismo e Interseccionalidade na Abordagem do Aumento do Encarceramento Feminino. Psicologia: Ciência e Profissão [online], Brasília, v. 38, n. 2, p. 27-43, 2018. ISSN 1982-3703. Disponivel em:

https://www.scielo.br/j/pcp/a/MHtjGhJrYXTLYzWmS6X4W6Q/?lang=pt\#. Acesso em: 03 Setembro 2021.

PINHEIRO, L. S. et al. Os desafios do passado no trabalho doméstico do século XXI: reflexões para o caso brasileiro a partir dos dados da PNAD Contínua. Textos para Discussão/IPEA. Brasília, Rio de Janeiro: IPEA, 2019. Disponivel em:

http://repositorio.ipea.gov.br/handle/11058/9538.

ROBERTS, D. E. Prison, Foster Care, and the Systemic Punishment of Black Mothers. UCLA Law Review, Pennsylvania, v. 59, n. 12-45, p. 1474-1502, 01 Agosto 2012. Disponivel em: https://papers.ssrn.com/sol3/papers.cfm?abstract_id=2184329. Acesso em: 19 Dezembro 2021.

ROCHA, L. Judicialização do Sofrimento Negro. Maternidade Negra e Fluxo do Sistema de Justiça Criminal no Rio de Janeiro. Sexualidad, Salud y Sociedad, Rio de Janeiro, n. 36, p. 181-205, set/dez 2020. Disponivel em:

https://www.scielo.br/j/sess/a/DMJwqFZpsWVDKtkzbWpQPBC/. Acesso em: 19 Dezembro 2021.

RODRIGUES, A. S. À procura de novos caminhos: mulheres negras e suas experiências a partir do sistema prisional do Rio de Janeiro (Dissertação de Mestrado em Serviço Social). Rio de Janeiro: Pontíficia Universidade Católica, 2010. 131 p. Disponivel em: https://www.maxwell.vrac.puc-

rio.br/colecao.php?strSecao=resultado\&nrSeq=16567@1. Acesso em: 10 setembro 2021.

SANTOS, B. R. M.; REZENDE, V. A. Sistema carcerário feminino: uma análise das políticas. Cadernos EBAPE, Rio de Janeiro, v. 03, n. 18, jul/set 2020. Disponivel em: https://www.scielo.br/j/cebape/a/nb3pxjFQ7hDkWFxJ9D8MzFc/?format=pdf\&lang=pt. Acesso em: 07 setembro 2021. 
TINOCO, D.; PELLEGRINO, A. P. Depois da Prisão - caminhos possíveis para mulheres. Instituto Igarapé. Rio de Janeiro. 2019.

\section{Notas}

${ }^{1}$ A luta por reconhecimento se materializa com os movimentos sociais desde a década de 1970 e, a partir da década de 1990 a discussão sobre o reconhecimento na filosofia frutifica para além da abordagem de Fraser. Isto posto, ressaltamos que não adentramos nos embates teóricos entre Fraser e outros/as autores/as, como Charles Taylor, Axel Honneth, Judith Butler e Iris Marion Young.

(c) (7) (5)

This work is licensed under a Creative Commons Attribution-NonCommercial 4.0 International (CC BY-NC 4.0) 